\title{
Correction to: Development of a Vaporizer for Gradual Vaporization Control of Precursor Materials in the CVD Process
}

\author{
Tae Min Kim ${ }^{1,2} \cdot$ Hyun Sik Sim ${ }^{2} \cdot$ Jae Wook Jeon ${ }^{1}$
}

Published online: 26 August 2021

(c) The Korean Institute of Metals and Materials 2021

\section{Correction to: \\ Electronic Materials Letters (2021) 17:250-259 \\ https://doi.org/10.1007/s13391-021-00280-1}

In the original publication of the article, the third author's affiliation was published incorrectly. The correct affiliation is given in this correction.

The original article has been corrected.

Publisher's Note Springer Nature remains neutral with regard to jurisdictional claims in published maps and institutional affiliations.

The original article can be found online at https://doi.org/10.1007/ s13391-021-00280-1.

$\triangle$ Jae Wook Jeon jwjeon@yurim.skku.ac.kr

1 Department of Semiconductor and Display Engineering, Sungkyunkwan University, Seoul, Republic of Korea

2 Memory Technology Innovation Team, Samsung Electronics Co., Ltd., Suwon-si, Republic of Korea 